\title{
Efficiency of Nanofiltration Membrane TFC-SR3 and SelRo MPF-34 for Partial Elimination of Fluoride and Salinity from Drinking Water
}

\author{
Mouhamadou A. Diallo', Saidou N. Diop², Mohamad M. Diémé2, Courfia K. Diawara ${ }^{2 *}$ \\ ${ }^{1} E$ Ecole Doctorale Eau Qualité et Usage de l'Eau, Université Cheikh Anta DIOP de Dakar, Dakar, Senegal \\ ${ }^{2}$ UFR Sciences et Technologies, Université Assane Seck de Ziguinchor, Ziguinchor, Senegal \\ Email: ${ }^{*}$ ckdiawara@univ-zig.sn
}

Received 24 February 2015; accepted 29 April 2015; published 5 May 2015

Copyright (C) 2015 by authors and Scientific Research Publishing Inc.

This work is licensed under the Creative Commons Attribution International License (CC BY).

http://creativecommons.org/licenses/by/4.0/

\section{(c) (i) 0pen Access}

\begin{abstract}
Consumption of safe drinking water is essential to human health. The excess of certain elements in drinking water causes health problem for people consuming these waters. In Senegal, the excessive levels of fluoride and salts found in the groundnut basin cause public health problem such as dental and/or skeletal fluorosis. Thus, the treatment of such waters is essential before consumption to prevent health problems. For a partial removal of fluoride and salinity, we tested the performance of two commercial nanofiltration membranes namely TFC-SR3 and SelRO MPF-34 at laboratory scale. The results showed that TFC-SR3 membrane was very efficient with rejection rates of $83 \%-96 \%$ for fluoride ions and $89 \%$ - 96\% for salinity. For SelRo MPF-34 membrane, retention rates of $25 \%-52 \%$ were obtained for fluoride ions and $24 \%-60 \%$ for the salinity.
\end{abstract}

\section{Keywords}

Fluoride, Nanofiltration, Rejection, Salinity

\section{Introduction}

In the groundnut basin of Senegal, high fluoride and salinity concentrations are found in groundwater [1]. Fluoride concentrations above $1.5 \mathrm{mg} / \mathrm{L}$ are known to cause dental fluorosis while those greater than $4 \mathrm{mg} / \mathrm{L}$ can cause crippling skeletal fluorosis [1] [2]. In Senegal, fluorosis is among the most common diseases due to water "Corresponding author. 
quality [3]. The problem not only affects public health, but also hinders rural activities such as agriculture and economic activities. The solution to the problem requires the implementation and development of effective methods of treatment at affordable costs.

The nanofiltration (NF) due to its ionic rejection characteristic can be an effective technology for the treatment of groundwater with high contents of salinity and fluoride [4]-[8]. Furthermore, the low pressure required for the functioning process facilitates its application in rural and isolated areas where grid power is not supplied, by using photovoltaic energy generated by solar cells [9]. The aim of our study was to investigate, at laboratory scale, the performance of two commercial nanofiltration membranes namely TFC-SR3 and SelRo MPF-34 for a partial removal of fluoride and salinity from groundnut basin of Senegal.

\section{Materials and Methods}

\subsection{Membranes and Equipment}

The membranes used in this work were TFC-SR3 and SelRo MPF-34 (Nanofiltration Inc. sterling), a TFC polymer membrane (TFC-SR3) and polymer proprietary (SelRo MPF-34). According to the manufacturer, these membranes have a nominal molecular weight cut off (MWCO) of 200 Dalton, with an operational pH range varying from 4 to 10 for TFC-SR3 membrane and from 0 to 14 for SelRo MPF-34 membrane.

\subsection{Experimental Procedure}

A commercial membrane module of $1.59 \times 10^{-3} \mathrm{~m}^{2}$ effective area in stainless steel pressure housing was incorporated into a membrane pilot system assembled in the laboratory. The system was skid-mounted using stainless steel feed tank of $2 \mathrm{~L}$ capacity. High pressure gas nitrogen capable of maintaining pressure up to 12 bars and feed flow rate of $20 \mathrm{~mL} / \mathrm{h}$ was installed at the dead end of the feed tank to facilitate the transport of feed solution through the membrane module. The membrane module was operated in frontal mode and all experiments were performed at ambient temperature. The solute rejection rate, $R(\%)$, was calculated based on the following equation:

$$
R=\left(1-\frac{C_{p}}{C_{f}}\right) \times 100
$$

where $C_{f}$ and $C_{p}$ are concentrations (mg/L) of the solute in the feed and permeate solutions respectively.

The retentions of salt were determined using an electrical conductivity meter (HI99300-HI99301 HANNA). The concentrations of fluoride were determined by using a colorimetric method in the SPADNS reagents with a "MULTIDIRECT" spectrophotometer while $\mathrm{pH}$ measurements are made by means of a $\mathrm{pH}$ meter WTW pH330i/SET.

In this work we had chosen six sampling sites among the three cities of Diourbel, Fatick and Kaolack and where the excess of fluoride and salinity is well-known. One sampling site is chosen both in rural area and urban area for each of the three cities. In rural area, the letter " $R$ " is used to name the sample while in urban area the letter "U" is used. So, samples taken in Fatick are named RF and UF for rural area and urban area respectively; the samples taken in Kaolack are named RK and UK for rural area and urban area respectively and finally the samples taken in Diourbel are named RD and UD for rural area and urban area respectively.

\section{Results and Discussion}

\subsection{Fluoride Concentration and Conductivity in the Feed Water for the Different Sites}

The results obtained show that fluoride concentration levels in the feed water was higher than the value recommended by world health organization (WHO) which is included between 0.5 and $1.5 \mathrm{mg} / \mathrm{L}$ (Figure 1).

The concentration of fluoride in all sites ranged from $2.6 \mathrm{mg} / \mathrm{L}$ and $4.45 \mathrm{mg} / \mathrm{L}$, thus exceeding the WHO guidelines and may have adverse effects on human health. For conductivity measurements, results obtained show also high values exceeding WHO guidelines. In fact, the conductivity in water analyzed in all the sites ranged from 1600 to $2560 \mu \mathrm{S} / \mathrm{cm}$ (Figure 2) while conductivity recommended in drinking water by WHO is $1000 \mu \mathrm{S} / \mathrm{cm}$. 


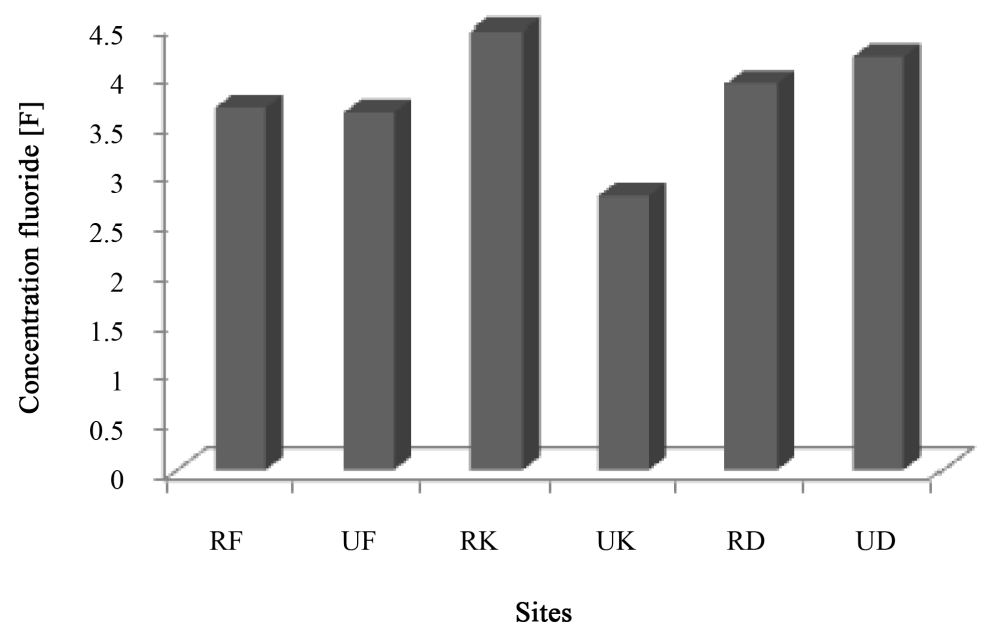

Figure 1. Fluoride concentration in the feed water.

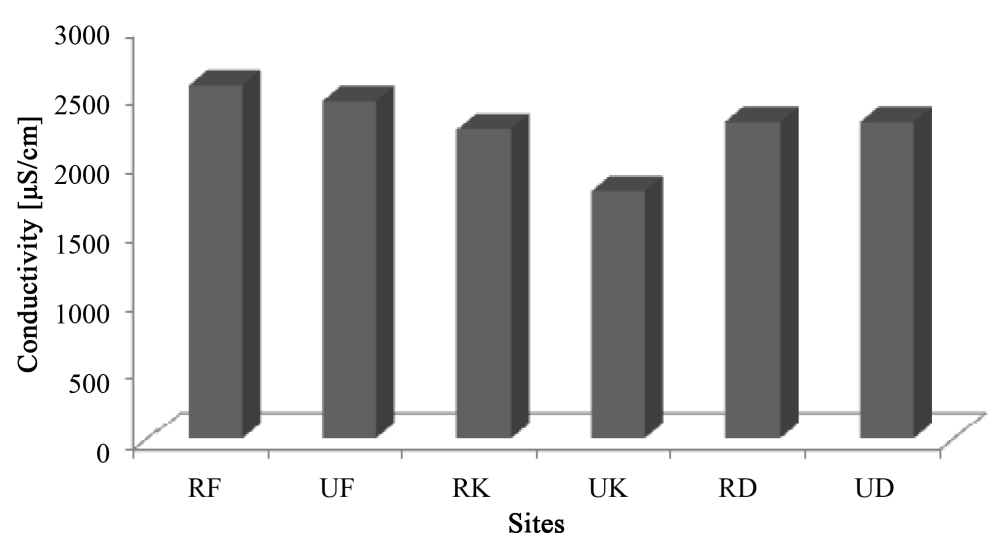

Figure 2. Conductivity in the feed water.

\subsection{Effect of the Trans-Membrane Pressure}

Nanofiltration is a pressure driven membrane process and the trans-membrane pressure (TMP) plays an important role in separations mechanisms. To investigate the influence of the TMP on permeation and rejection, a solution with fluoride concentration of $4.28 \mathrm{mg} / \mathrm{L}$ was used as the feed at $\mathrm{pH}$ 8.0. Permeation fluxes and rejection of fluoride by TFC-SR3 membrane with TMP varying in the range of 8 - 14 bar are depicted in the Figure 3. With the increase of the TMP, the permeation flux increased linearly and the retention increase also before remaining nearly constant at given pressure, 10 bar in our case. At a high TMP, the transport of water molecules accelerates [10], but the TMP did not accelerate the diffusion of solute ions [11], thus the permeation concentration decreased, resulting in higher fluoride retention. At 8 bars, the retention of fluoride was about $87 \%$ and the permeation flux was $12.5 \mathrm{~L} / \mathrm{m}^{2} \cdot \mathrm{h}$.

\subsection{Fluoride Rejection}

Experimental data on fluoride rejection according to filtration time for TFC-SR3 and SelRo MPF-34 membranes are displayed in Figure 4. During a filtration period ranging from 1 to 30 hours, the rejection rate of fluoride was fairly constant with a value of 95\% for TFC-SR3 membrane while for the SelRo MPF-34 membrane we noticed a slight increase of the fluoride rejection rate from $45 \%$ to $54 \%$. Beyond 30 hours of filtration, the fluoride rejection rate gradually decreases from $95 \%$ to $83 \%$ and from $54 \%$ to $24 \%$ for TFC-SR3 membrane and for SeIRo MPF-34 membrane, respectively.

The results showed that the TFC-SR3 membrane is more effective and suitable than SelRo MPF-34 membrane for reducing the excess of fluoride and salts in drinking water. The difference on the rejection of salts and 


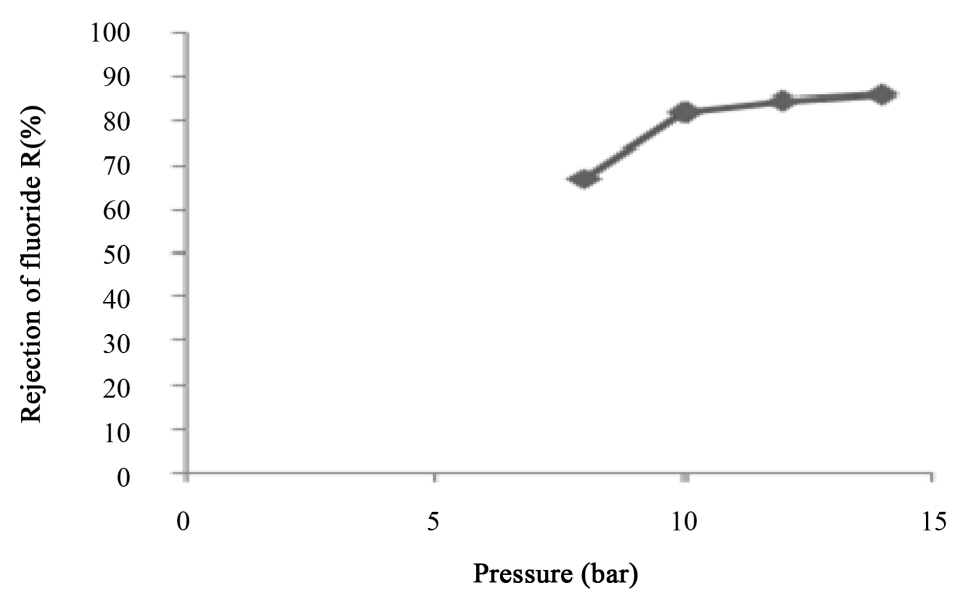

Figure 3. Influence of TMP on fluoride rejection $\left(\left[\mathrm{F}^{-}\right]=4.28 \mathrm{mg} / \mathrm{L}, \mathrm{pH}=8\right)$.

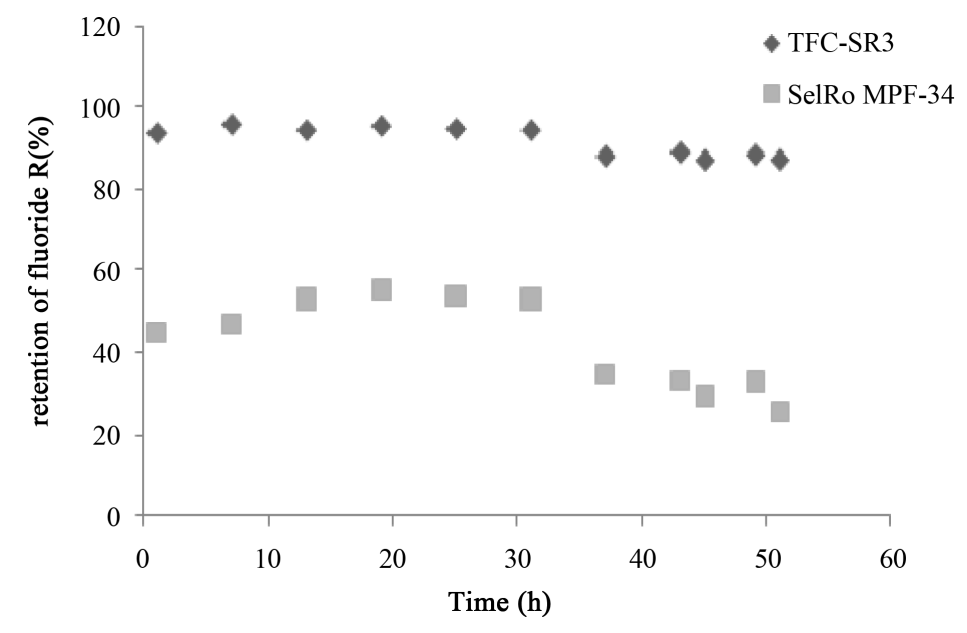

Figure 4. Fluoride rejection in function to time.

fluoride between TFC-SR3 and SelRo MPF-34 membranes was due to difference of intrinsic properties of these membranes. The decline of the rejection rate for fluoride was assumed to be due to the membrane fouling [3] (Figure 5), beyond 30 hour the permeate flux decreases gradually from 13 to $8 \mathrm{~L} / \mathrm{m}^{2} \cdot \mathrm{h}$ for TFC-SR3 membrane and 19 to $9 \mathrm{~L} / \mathrm{m}^{2} \cdot h$ for SelRo MPF-34 membrane. In general, the rejection of ions in NF membrane process can be explained by Donnan exclusion and electrostatic repulsion.

The results of Figure 5 show that the flux remains constant between 1 to 30 hours for the TFC-SR3 membrane beyond the flux decreases to $7 \mathrm{~L} / \mathrm{m}^{2} \cdot \mathrm{h}$ at 61 hours. While for SelRo MPF-34 membrane, the flux remains constant from 1 to 24 hours beyond it decreases to $9 \mathrm{~L} / \mathrm{m}^{2} \cdot \mathrm{h}$ at 61 hours functioning. The decrease in flux may be due to fouling membrane [3]. It emerges from these results that the permeability of SelR MPF-34 membrane is higher and that fouling phenomena happen very quickly with the TFC-SR3 membrane.

\subsection{Salinity Rejection}

Salt rejection is an important factor to evaluate the electrostatic repulsion properties of the NF membrane. For charged NF membranes, the performance of ion separation is controlled primarily by Donnan exclusion effect which increases with membrane charge [12]. Because ion strength is too high in seawater, Donnan exclusion mechanism could not be used to explain the observation from a view of surface charge. Salt rejection by NF membrane could be influenced by the combination of the size exclusion and diffusion control theories [13]. During the long-term operation, the salt rejection (calculated by conductivity) was measured (Figure 6). The rejection rate of conductivity is constant during the experience with TFC-SR3 membrane, it was about $96 \%$. But 


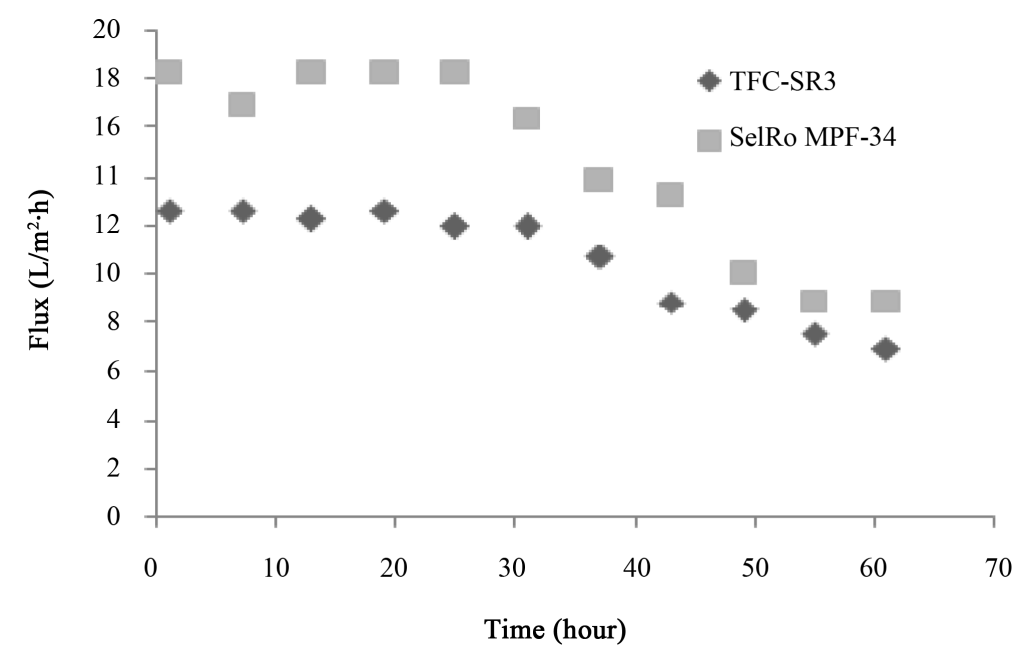

Figure 5. Permeate fluxes.

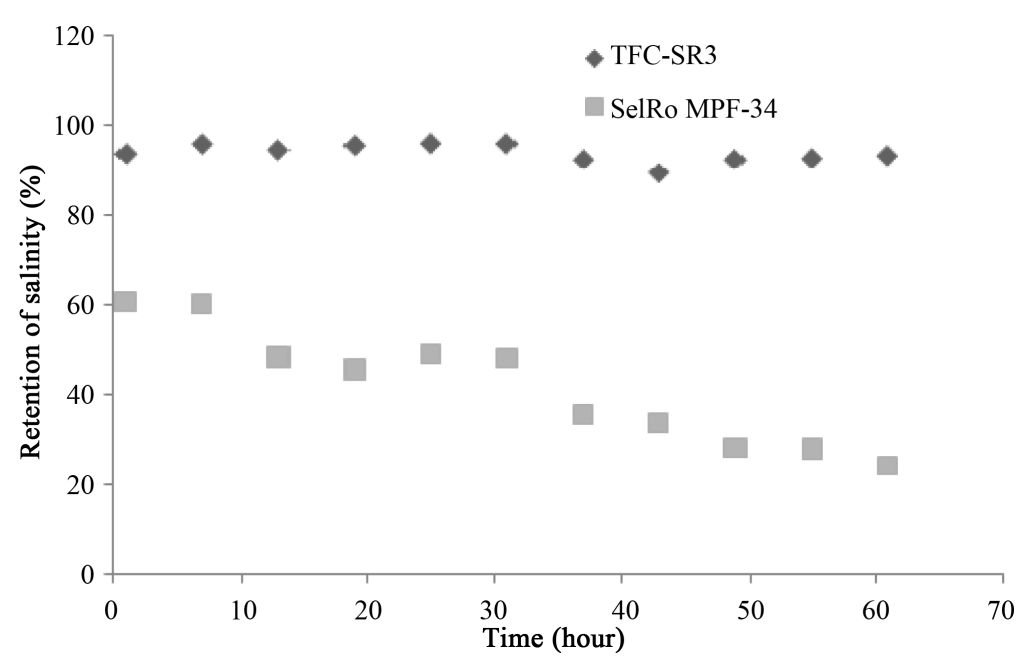

Figure 6. Salts rejection in function to time.

for SelRo MPF-34 the rejection rate is constant during 7 hour, beyond the rejection rate decreases gradually till $27 \%$ at 61 hour functioning.

\section{Conclusion}

Use of NF membranes is steeply increasing in industrial separation processes, leading to considerable research efforts. Apart from the economical advantages due to the decrease of operational costs when using NF instead of more traditional procedures, the improvement of performances makes them particularly attractive. In the present study, two commercial NF membranes have been used for validating experimental data of fluoride and salt rejection. In this study we noticed that the concentration of fluoride and conductivity in the samples of feed water from groundnut basin in Senegal are higher than those recommended by the WHO. The experimental data show that, the TFC-SR3 membrane is more effective and more suitable than the SelRo MPF-34 membrane with a rejection rate of fluoride varying from $87 \%$ to $95 \%$ and the salt rejection was constant at nearly $96 \%$, whereas for the SelRo MPF-34 membrane, the fluoride rejection rate and salt varied respectively from $25 \%$ to $52 \%$ and $24 \%$ to $60 \%$. The experimental data show that, the fluoride rejection decreases according to time due to the membrane fouling. In the future, characterizations studies such as measurement of the density of surface charge, zeta potentials, atomic force microscopy and scanning electron microscopy measurements of the membranes are expected. Furthermore, the application of these results in sites is planned to be done. 


\section{References}

[1] Lhassani, A., Diawara, C.K., Elana, A., Innocent, C., Aureau, D., Rumeau, M., Croue, J.P., Buisson, H. and Hemery, P. (2004) Seawater Nanofiltration for the Elaboration of Usable Salty Waters. Desalination, 167, 347-355. http://dx.doi.org/10.1016/j.desal.2004.06.144

[2] Paugam, L., Diawara, C.K., Schlumpf, J.P., Jaouen, P. and Quéméneur, F. (2004) Transfer of Monovalent Anions and Nitrates Especially through Nanofiltration Membranes in Brackish Water Conditions. Separation and Purification Technology, 40, 237-242. http://dx.doi.org/10.1016/j.seppur.2004.02.012

[3] Diawara, C.K., Diop, S.N., Diallo, M.A., Farcy, M. and Deratani, A. (2011) Performance of Nanofiltration (NF) and Low Pressure Reverse Osmosis (LPRO) Membrane in the Removal of Fluorine and Salinity from Brackish Drinking Water, Journal of Water Resource and Protection, 3, 912-917. http://dx.doi.org/10.4236/jwarp.2011.312101

[4] Antonio, P.P. and Hugo, S. (2010) Performance of Simultaneous Arsenic, Fluoride and Alkalinity (Bicarbonate) Rejection by Pilot-Scale Nanofiltration. Desalination, 257, 16-21. http://dx.doi.org/10.1016/j.desal.2010.03.022

[5] Walha, K., Ama, R.B., Bourseau, P. and Jaouen, P. (2009) Nanofiltration of Concentrated and Salted Tuna Cooking Juices. Process Safety and Environmental Protection, 87, 331-335. http://dx.doi.org/10.1016/j.psep.2009.04.002

[6] Bourseau, P., Vandanjon, L., Jaouen, P., Chaplain-Derouiniot, M., Masse, A., Guerard, F., Chabeaud, A., FouchereauPeron, M., LeGal, Y., Ravallec-Ple, R., Berge, J.P., Picot, L., Piot, J.M., Batista, I., Thorkelsson, G., Delannoy, C., Jakobsen, G. and Johansson, I. (2009) Fractionation of Fish Protein Hydrolysates by Ultrafiltration and Nanofiltration: Impact on Peptidic Populations. Desalination, 244, 303-320. http://dx.doi.org/10.1016/j.desal.2008.05.026

[7] Van der Bruggen, B. and Vandecasteele, C. (2003) Removal of Pollutants from Surface Water and Groundwater by Nanofition: Overview of Possible Applications in the Drinking Water Industry. Environmental Pollution, 122, 435445. http://dx.doi.org/10.1016/S0269-7491(02)00308-1

[8] White, L.S. (2006) Development of Large-Scale Applications in Organic Solvent Nanofiltration and Pervaporation for Chemical and Refining Processes. Journal of Membrane Science, 286, 26-35. http://dx.doi.org/10.1016/j.memsci.2006.09.006

[9] Bowen, W.R., Mohammad, A.W. and Hilal, N. (1997) Characterisation of Nanofiltration Membranes for Predictive Purposes: Use of Salts, Uncharged Solutes and Atomic Force Microscopy. Journal of Membrane Science, 126, 91-102. http://dx.doi.org/10.1016/S0376-7388(96)00276-1

[10] Al-Zoubi, H. and Omar, W. (2009) Rejection of Salt Mixtures from High Saline by Nanofiltration Membranes. Korean Journal of Chemical Engineering, 26, 799-805. http://dx.doi.org/10.1007/s11814-009-0133-7

[11] Hilal, N., Al-Zoubi, H., Mohammad, A.W. and Darwish, N.A. (2005) Nanofiltration of Highly Concentrated Salt Solutions up to Seawater Salinity. Desalination, 184, 315-326. http://dx.doi.org/10.1016/j.desal.2005.02.062

[12] Mukherjee, P., Jones, K.L. and Abitoye, J.O. (2005) Surface Modification of Nanofiltration Membranes by Ion Implantation. Journal of Membrane Science, 254, 303-310. http://dx.doi.org/10.1016/j.memsci.2005.01.004

[13] Chen, S.S., Taylor, J.S., Mulford, L.A. and Norris, C.D. (2004) Influences of Molecular Weight, Molecular Size, Flux, and Recovery for Aromatic Pesticide Removal by Nanofiltration Membranes. Desalination, 160, 103-111. http://dx.doi.org/10.1016/S0011-9164(04)90000-8 